Journal of Biotechnology and Strategic Health Research

Araştırma Makalesi / Research Articl

http://dergipark.org.tr/tr/pub/bshr

\title{
Sağlık Çalışanlarında COVID-19 Temas Durumu, Risk Kategorisi ile Sonrasında Oluşan Klinik Tablonun ve Prognozun Araştırılması: Erken Pandemi Deneyimi
}

\author{
Investigation of COVID-19 Exposure, Risk Category and Subsequent Clinical Picture \\ and Prognosis in Healthcare Professionals: Early Pandemic Experience
}

(iD $\triangle$ Taylan Önder, (iD Sevil Alkan, (D) Ebru Doğan, (iD Alper Şener

Çanakkale Onsekiz Mart Üniversitesi Tıp Fakültesi Enfeksiyon Hastalıkları ve Klinik Mikrobiyoloji Ana Bilim Dalı, Çanakkale

ORCID ID: Taylan Önder https://orcid.org/0000-0003-0684-4047, Sevil Alkan https://orcid.org/0000-0003-1944-2477,

Ebru Doğan https://orcid.org/0000-0001-6458-6408, Alper Şener https://orcid.org/0000-0003-2774-8601

^Sorumlu Yazar / Corresponding Author: Arş. Gör. Dr. Taylan Önder, e-posta / e-mail: taylanonder@hotmail.com

Geliş Tarihi / Received : 04-10-2021 Kabul Tarihi / Accepted: 27-10-2021 Yayın Tarihi / Online Published: 30-12-2021

Önder T., Alkan S., Doğan E., Şener A. Sağlık Çalışanlarında COVID-19 Temas Durumu, Risk Kategorisi ile Sonrasında Oluşan Klinik

Tablonun ve Prognozun Araştırılması: Erken Pandemi Deneyimi, J Biotechnol and Strategic Health Res. 2021; 5(3):207-213

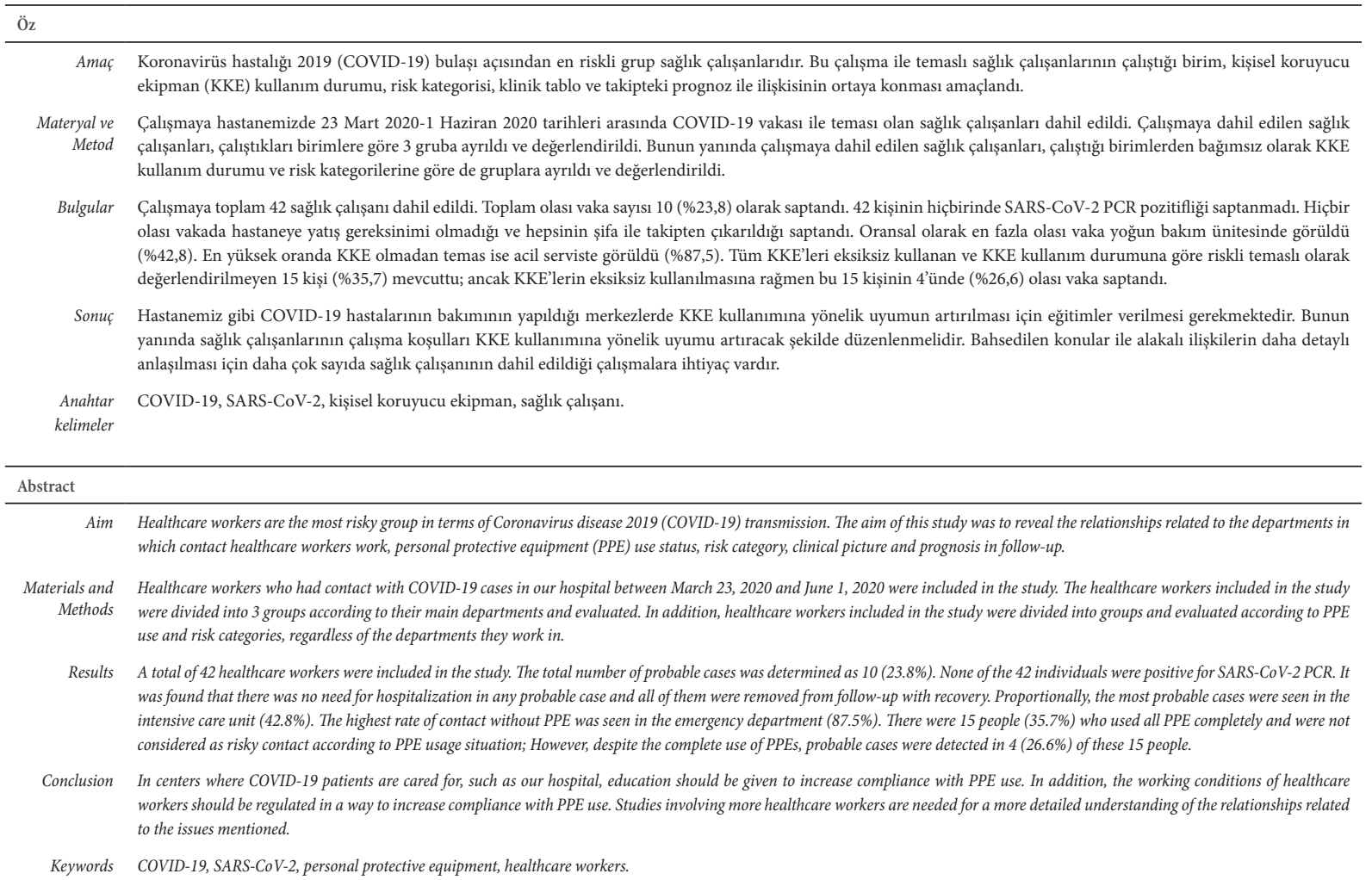




\section{GíRiş}

Dünya Sağlık Örgütü (DSÖ) tarafından ilk olarak 31 Aralık 2019'da Çin Hubei eyaleti Wuhan şehrinde etiyolojisi bilinmeyen pnömoni vakaları bildirilmiştir. Yapılan araştırmalar sonucunda Ocak 2020'de bu pnömoni vakalarının daha önce insanda saptanmamış yeni bir tip koronavirüse bağlı olduğu ortaya çıkmıştır. ${ }^{1}$ Hastalığa sebep olan virüs SARS-CoV’un da içinde bulunduğu Betacoronavirus cinsi içinde Sarbecovirus alt cinsi altında sınıflandırılmıştır ve ilk önce 2019-nCoV (2) olarak isimlendirilmiş olup sonrasında SARS-CoV’a yakın benzerliğinden dolayı SARSCoV-2 olarak isimlendirilmiştir., ${ }^{2,3} \mathrm{Bu}$ virüsün neden olduğu hastalık da Koronavirüs hastalığı 2019 (COVID-19) olarak isimlendirilmiştir. ${ }^{4}$ COVID-19 salgını başlangıçta Wuhan şehrinde bölgesel bir salgın olarak seyir etmiştir, ancak vakalar hızla artmaya devam etmiş olup küresel çapta yayılmıştır ve 11 Mart 2020'de DSÖ tarafından pandemi olarak kabul edilmiştir. ${ }^{5}$ Ülkemizde de komşu ülkelerden sonra ilk vaka 11 Mart 2020'de görülmüştür. ${ }^{6}$ Günümüzde tüm dünyada olduğu gibi ülkemizde de vaka sayıları giderek artmaktadır. Hastalık insandan insana bulaşma özelliği göstermektedir. Esas bulaşma yolu damlacık yoluyla olmaktadır. Semptomatik veya asemptomatik enfekte bireylerin öksürme, hapşırma yoluyla ortama saçtığ1 damlacıklara temas sonrası bu damlacıkların mukozalara götürülmesi ile de bulaşma olabilmektedir. ${ }^{7}$ Virüs, canlı olmayan yüzeylerde de $22-25^{\circ} \mathrm{C}$ 'de, $\% 40$-50 bağıl nemde 5 güne kadar aktif kalabildiği için cansız yüzeylerden bulaş da söz konusudur. ${ }^{8}$ Virüs solunum sekresyonları dışında ter hariç hemen hemen tüm vücut sıvılarında bulunabilmektedir. ${ }^{8}$ Özellikle virüsün dışkıda saptanması ve 1 ayı aşkın sürelerde dışkı ile atılması virüsün fekal-oral veya fekal-damlacık yolu ile bulaşabileceği ihtimalini de gündeme getirmiştir. ${ }^{9}$ Hastalığın çoğalabilme hızı (R0 değeri) Çin'de Wuhan bölgesinde yapılan ilk çalışmalarda 2.3-3.3 düzeylerinde iken tüm Çin genelinden elde edilen veriler doğrultusunda çoğalabilme hızının 5.7 gibi yüksek rakamlara ulaşabildiği gösterilmiştir. ${ }^{10}$ Bu veriler bize hastalığın yüksek düzeyde bulaştırıcı olabileceğini ve sıkı bir şekilde hem kişisel hem de toplumsal enfeksiyon kontrol önlem- lerine uymamız gerektiğini göstermektedir. SARS-CoV-2 enfeksiyonuna toplumun tümü duyarlıdır. COVID-19 bulaşı açısından en fazla risk altındaki grup kesin pozitif vakalar ile en çok yakın temasta bulunan popülasyon olması nedeniyle sağlık çalışanlarıdır. 20 Eylül 2020 tarihli değerlendirme raporuna göre bu tarihe kadar ülkemizde COVID-19'a yakalanan sağlık çalışanı sayısı 29865 olarak saptanmıştır. Bu sayı bu tarihe kadar olan toplam vakaların \%10,9'unu oluşturmaktadır. Bu tarihe kadar vefat eden sağlık çalışanı sayısı ise 52 olup toplam vefat sayısına oranı \%0,8'dir. Yine bu rapora göre ülkemizde sağlık çalışanlarının COVID-19'a yakalanma oranı topluma göre 8,48 kat fazla bulunmuştur. ${ }^{11}$

COVID-19 hastalarının bakımının yapıldığı merkezlerde çalışma alanında korunma önlemlerine, direkt temas ve damlacık izolasyonu kurallarına uyulması, aerosol oluşturan işlemlerde de solunum izolasyonu kurallarına sıkı bir şekilde uyulması gerekmektedir. Bu izolasyon kuralları doğrultusunda çalışanların uygun kişisel koruyucu ekipman (KKE) kullanımına tam olarak uyması çok önemlidir. Uygun korunma olmadan riskli temas sonrası sağlık çalışanları arasında COVID-19 vakaları ortaya çıkabilmektedir. Ayrıca COVID-19 pozitif sağlık çalışanı vasıtası ile hastanede ve COVID-19 hastalarının bakımının yapıldığı merkezlerde salgınlar görülebilmektedir. $\mathrm{Bu}$ salgınların ciddi bir iş gücü kaybı da meydana getireceği unutulmamalıdır. Türkiye Cumhuriyeti Sağlık Bakanlığı ve Dezenfeksiyon Antisepsi Sterilizasyon (DAS) Derneği, KKE çeşitleri ve KKE’lerin doğru kullanımı KKE'lerin doğru kullanılmadığında oluşacak riskli temasların kategorizas yonu ile ilgili önerilerini sunmuştur. ${ }^{12-14}$

Hastanemiz 23.03.2020 tarihinden itibaren COVID-19 pandemi hastanesi olarak çalışmaya başladığından bu yana COVID-19 şüpheli hastaların başvurduğu, tanı ve tedavi hizmetlerinin gerçekleştirildiği başlıca merkez haline gelmiştir. Bu yüzden hastanemizde çalışan sağlık personeli sık bir şekilde COVID-19 kesin ve olası vakaları ile yakın temas halinde olmaktadır ve bu durum da riskli temas ola- 
sılığını arttırmaktadır. Biz de bu bağlamda hastanemizde temas öyküsü olan sağlık çalışanlarının çalıştığı birim ile temas arasındaki ilişkiyi, risk kategorisini, temas sonrasındaki takipte klinik tablo gelişip gelişmediği ve klinik tablo gelişen çalışanların prognozlarını değerlendirmek amacıyla bu çalışmayı planladık. Bu çalışmadan elde edilen veriler ışığında, hastanemizde çalışan temas öyküsü olan sağlık çalışanlarında KKE’lerin hangilerine uyumun yüksek olup hangilerine düşük olduğu, risk kategorisi, klinik tablo gelişip gelişmediği ve klinik tablo gelişen çalışanların prognozları, KKE eksiksiz kullanımına rağmen klinik tablo görülüp görülmediği gibi sorulara cevap bulunması amaçlandı.

\section{GEREÇ ve YÖNTEM}

Çalışma gözlemsel, tanımlayıcı tipte bir epidemiyolojik çalışmadır. Çalışma için T.C. Sağlık Bakanlığı, Sağlık Hizmetleri Genel Müdürlüğü COVID-19 Bilimsel Araştırma Değerlendirme Komisyonu'ndan 04.05.2020 tarihli ve üniversitemiz Klinik Araştırmalar Etik Kurulu'ndan 03.06.2020 tarihli onay alındı. Çalışmaya hastanemizde 23 Mart 2020-1 Haziran 2020 tarihleri arasında COVID-19 vakası ile teması olan sağlık çalışanları dahil edildi. Teması olan sağlık çalışanlarının demografik verileri, çalıştığı birimler, KKE kullanım durumları, risk kategorileri ile ilgili veriler hastane enfeksiyon kontrol komitesinden, klinik ve laboratuar verileri ise hastane otomasyon sisteminden elde edildi. Çalışmaya dahil edilen sağlık çalışanları, çalıştığı ana birimler olan acil servis, yoğun bakım ünitesi ve COVID-19 servisi birimlerine göre 3 gruba ayrıldı ve bu gruplar arasında KKE kullanım durumu, risk kategorisi, temas sonrasındaki takipte klinik tablo gelişip gelişmediği, SARS-CoV-2 PCR pozitifliği ve klinik tablo gelişen çalışanların prognozları değerlendirildi. Bunun yanında çalışmaya dahil edilen sağlık çalışanları, çalıştığı birimlerden bağımsız olarak KKE kullanım durumu ve risk kategorilerine göre de gruplara ayrıldı ve bu gruplar arasında temas sonrasındaki takipte klinik tablo gelişip gelişmediği, SARS-CoV-2 PCR pozitifliği ve klinik tablo gelişen çalışanların prognozları değerlendirildi.

\section{BULGULAR}

Çalışmaya toplam 42 sağlık çalışanı dahil edildi. Çalışmadaki sağlık çalışanlarının yaş ortalaması $31.4333 \pm 2.266( \pm 7.21 \%)$ olarak saptand1, 31'i $(\% 73,8)$ kadın, 11'i $(\% 26,2)$ erkekti. Temas sonrası meydana gelen toplam olası vaka sayısı $10(\% 23,8)$ olarak saptandı. Temas sonrası olası vakalar görünmesine rağmen değerlendirilen 42 kişinin hiçbirinde SARS-CoV-2 PCR pozitifliği olmad1ğ1 görüldü. Hiçbir olası vakada hastaneye yatış gereksinimi olmadığı ve hepsinin şifa ile takipten çıkarıldığı saptandı. Acil serviste çalışan teması olan sağlık çalışanı sayısı 16 idi $(\% 38,09)$ ve bu kişilerin 2'sinin $(\% 12,5)$ olası vaka olduğu saptandı. Bu kişilerin KKE kullanım durumları; KKE kullanmayan 14 kişi $(\% 87,5)$, eksiksiz KKE kullanımı olan 2 kişi $(\% 12,5)$ şeklindeydi. 14 kişi $(\% 87,5)$ yüksek riskli temas olarak değerlendirilirken, 2 kişinin $(\% 12,5)$ teması riskli temas olarak değerlendirilmedi.

Yoğun bakım ünitesinde çalışan teması olan sağlık çalışanı sayısı 7 idi $(\% 16,6)$ ve bu kişilerin 3'ünün $(\% 42,8)$ olası vaka olduğu saptandı. Bu kişilerin KKE kullanım durumları; KKE yok 4 kişi $(\% 57,2)$, eksiksiz KKE kullanımı 3 kişi $(\% 42,8)$ şeklindeydi. 4 kişi $(\% 57,2)$ yüksek riskli temas olarak değerlendirilirken 3 kişinin $(\% 42,8)$ teması riskli temas olarak değerlendirilmedi.

COVID-19 servisinde çalışan teması olan sağlık çalışanı sayısı 19 idi $(\% 45,23)$ ve bu kişilerin 5'inin $(\% 26,3)$ olası vaka olduğu saptandı. Bu kişilerin KKE kullanım durumları; KKE yok 7 kişi $(\% 36,9)$, yanlış maske kullanımı 1 kişi $(\% 5,2)$, göz koruyucu yok 1 kişi $(\% 5,2)$, eksiksiz KKE kullanımı 10 kişi $(\% 52,7)$ şeklindeydi. 7 kişi $(\% 36,9)$ yüksek riskli temas, 2 kişi $(\% 10,4)$ orta riskli temas olarak değerlendirilirken 10 kişinin $(\% 52,7)$ teması riskli temas olarak değerlendirilmedi.

Çalışmamızda temaslı sağlık çalışanları, çalıştığı birimlerden bağımsız olarak KKE kullanım durumu ve risk kategorilerine göre de gruplara ayrıldı ve değerlendirildi. 
Kırk iki temaslı sağlık çalışanının 25'inde $(\% 59,5) \mathrm{KKE}$ yoktu, 1'inde $(\% 2,4)$ yanlış maske kullanımı vardı, 1'inde $(\% 2,4)$ göz koruyucu yoktu ve 15 'inde $(\% 35,7)$ KKE kullanımı eksiksiz olarak saptandı ve bu kişilerde sırasıyla şu sayı ve oranlarda olası vaka saptand $[$ [(5 (\%20), 1 (\%100), 0, 4(\%26,6)]. 42 temaslı sağlık çalışanının 25'inde $(\% 59,5)$ yüksek riskli temas, 2 'sinde $(\% 4,8)$ orta riskli temas saptandı, $15(\% 35,7)$ sağlık çalışanının teması riskli temas olarak değerlendirilmedi ve bu kişilerde sırasıyla şu sayı ve oranlarda olası vaka saptand $15(\% 20), 1$ (\%50), $4(\% 26,6)]$. Çalışmadaki temaslı sağlık çalışanları ile ilgili veriler Tablo 1,2 ve 3 'te özetlendi.

\begin{tabular}{|l|c|c|c|}
\hline \multicolumn{1}{|l|}{$\begin{array}{l}\text { Tablo 1. Çalışılan birimler arası kişisel koruyucu ekipman kullanım } \\
\text { durumlarının incelenmesi }\end{array}$} & $\begin{array}{c}\text { ACİL } \\
\text { SERVİS }\end{array}$ & $\begin{array}{c}\text { YOĞUN } \\
\text { BAKIM } \\
\text { ÜNİTESİ }\end{array}$ & $\begin{array}{c}\text { COVID-19 } \\
\text { SERVİsI }\end{array}$ \\
\hline & n (\%) & n (\%) & n (\%) \\
\hline KKE YOK & $14(87,5)$ & $4(57,2)$ & $7(36,9)$ \\
\hline MASKE YOK & $0(0,0)$ & $0(0,0)$ & $0(0,0)$ \\
\hline $\begin{array}{l}\text { YANLIŞ MASKE } \\
\text { KULLANIMI }\end{array}$ & $0(0,0)$ & $0(0,0)$ & $1(5,2)$ \\
\hline GÖZ KORUYUCU YOK & $0(0,0)$ & $0(0,0)$ & $1(5,2)$ \\
\hline ELDİVEN-ÖNLÜK YOK & $0(0,0)$ & $0(0,0)$ & $0(0,0)$ \\
\hline EKSİKSİZ KKE KULLANIMI & $2(12,5)$ & $3(42,8)$ & $10(52,7)$ \\
\hline $\begin{array}{l}\text { \%: sütun yüzdesi } \\
\text { ^KKE: kişisel koruyucu ekipman }\end{array}$ & & \\
\hline
\end{tabular}

\begin{tabular}{|c|c|c|c|}
\hline & $\begin{array}{c}\text { ACİL } \\
\text { SERVİS }\end{array}$ & $\begin{array}{c}\text { YOĞUN } \\
\text { BAKIM } \\
\text { ÜNİTESI }\end{array}$ & $\begin{array}{l}\text { COVID-19 } \\
\text { SERVİSí }\end{array}$ \\
\hline & n (\%) & n (\%) & n (\%) \\
\hline \multicolumn{4}{|c|}{ OLASI VAKA } \\
\hline Yok & $14(87,5)$ & $4(57,2)$ & $14(73,7)$ \\
\hline Var & $2(12,5)$ & $3(42,8)$ & $5(26,3)$ \\
\hline \multicolumn{4}{|c|}{ SARS-CoV-2 PCR POZİTİFLİĞİ } \\
\hline Yok & $16(100,0)$ & $7(100,0)$ & $19(100,0)$ \\
\hline Var & $0(0,0)$ & $0(0,0)$ & $0(0,0)$ \\
\hline \multicolumn{4}{|c|}{ OLASI VAKALARDA YATIŞ } \\
\hline Yok & $2(100,0)$ & $3(100,0)$ & $5(100,0)$ \\
\hline Var & $0(0,0)$ & $0(0,0)$ & $0(0,0)$ \\
\hline \multicolumn{4}{|c|}{ OLASI VAKALARDA ŞİFA } \\
\hline Yok & $0(0,0)$ & $0(0,0)$ & $0(0,0)$ \\
\hline Var & $2(100,0)$ & $3(100,0)$ & $5(100,0)$ \\
\hline \multicolumn{4}{|c|}{ \%: sütun yüzdesi } \\
\hline
\end{tabular}

\begin{tabular}{|c|c|c|c|c|c|c|}
\hline & KKE YOK & MASKE YOK & $\begin{array}{l}\text { YANLIŞ MASKE } \\
\text { KULLANIMI }\end{array}$ & $\begin{array}{c}\text { GÖZ KORUYUCU } \\
\text { YOK }\end{array}$ & $\begin{array}{l}\text { ELDIVEN-ÖNLÜK } \\
\text { YOK }\end{array}$ & $\begin{array}{c}\text { EKSİKSİZ KKE } \\
\text { KULLANIMI }\end{array}$ \\
\hline & n (\%) & n (\%) & n (\%) & n (\%) & n (\%) & n (\%) \\
\hline \multicolumn{7}{|c|}{ OLASI VAKA } \\
\hline Yok & $20(80,0)$ & $0(0,0)$ & $0(0,0)$ & $1(100,0)$ & $0(0,0)$ & $11(73,4)$ \\
\hline Var & $5(20,0)$ & $0(0,0)$ & $1(100,0)$ & $0(0,0)$ & $0(0,0)$ & $4(26,6)$ \\
\hline \multicolumn{7}{|c|}{ SARS-CoV-2 PCR POZİTİFLİĞİ } \\
\hline Yok & $25(100,0)$ & $0(0,0)$ & $1(100,0)$ & $1(100,0)$ & $0(0,0)$ & $15(100,0)$ \\
\hline Var & $0(0,0)$ & $0(0,0)$ & $0(0,0)$ & $0(0,0)$ & $0(0,0)$ & $0(0,0)$ \\
\hline \multicolumn{7}{|c|}{ OLASI VAKALARDA YATIŞ } \\
\hline Yok & $5(100,0)$ & $0(0,0)$ & $1(100,0)$ & $0(0,0)$ & $0(0,0)$ & $4(100,0)$ \\
\hline Var & $0(0,0)$ & $0(0,0)$ & $0(0,0)$ & $0(0,0)$ & $0(0,0)$ & $0(0,0)$ \\
\hline \multicolumn{7}{|c|}{ OLASI VAKALARDA ŞIFA } \\
\hline Yok & $0(0,0)$ & $0(0,0)$ & $0(0,0)$ & $0(0,0)$ & $0(0,0)$ & $0(0,0)$ \\
\hline Var & $5(100,0)$ & $0(0,0)$ & $1(100,0)$ & $0(0,0)$ & $0(0,0)$ & $4(100,0)$ \\
\hline
\end{tabular}




\section{TARTIŞMA}

COVID-19 temaslı sağlık çalışanlarının değerlendirilmesi, COVID-19 pandemisinin en ön saflarında çalışan ve COVID-19 bulaş riski en yüksek grup olan sağlık çalışanlarının korunmasını sağlamak için büyük önem arz etmektedir. Öte yandan COVID-19'a yönelik sağlık hizmeti verilen birimlerde salgınların önlemesi ve iş gücü kaybının engellenmesi için de bu değerlendirmelerin yapılması gerekmektedir. Sağlık hizmetinde görülen bu gibi olumsuz durumların önlenmesi için temaslı sağlık çalışanlarının çalıştığı birim, KKE kullanım durumu, risk kategorisi, klinik tablo ve takipteki prognoz ile alakalı ilişkilerin ortaya konması gerekmektedir. Bu bağlamda bu çalışma planlandi.

Çalışmamızda değerlendirilen 42 sağlık çalışanının hiçbirinde SARS-CoV-2 PCR pozitifliği saptanmamış olup, bu durum çalışmanın bir sınırlılığı olarak değerlendirilebilir; ancak bu 42 kişinin içerisinde T.C. Sağlık Bakanlı̆̆ı kılavuzlarındaki öneriler doğrultusunda $10(\% 23,8)$ kişinin COVID-19 olası vaka tanımlamalarına uyduğu ve bu doğrultuda gerekli takip ve tedavilerinin yapıldı $\breve{g}_{1}$ saptandı. ${ }^{14-16}$

Çalışma biriminin olası vaka olma üzerine etkisinin değerlendirildiği bu çalışmada oransal olarak en fazla olası vaka yoğun bakım ünitesinde saptandı $(\% 42,8)$. Folgueira ve ark. ${ }^{17}$ tarafından yapılan bir çalışmada da, benzer şekilde yoğun bakım ünitesinde çalışan sağlık çalışanlarında, COVID-19 servis ve acil serviste çalışanlara kıyasla daha yüksek oranda COVID-19 tanısı konmuştur. Yoğun bakım ünitelerinde entübasyon ve solunum sekresyon aspirasyonu gibi aerosol oluşturan işlemler diğer birimlere kıyasla daha sık ve yoğun bir şekilde yapılmakta olup, bundan dolayı yoğun bakım ünitelerinde çalışan sağlık çalışanlarında daha sık COVID-19 vakası görüldüğü sonucu çıkarılabilir. Çalışma birimleri arasında yapılan KKE uyum değerlendirilmesinde en yüksek oranda KKE olmadan temasın görüldüğü birim acil servis olmuştur $(\% 87,5)$. Yoğun bakım ünitesi ve COVID-19 serviste çalışan sağlık çalışanları aralıklı olarak sadece hastaya müdahale edilmesi gereken zamanlarda hasta ile temas halinde olmaktadır ve bu zamanlarda KKE kullanıp diğer zamanlarda dinlenme alanlarında vakitlerini geçirebilmektedir; ancak acil serviste çalışan sağlık çalışanları 24 saatlik nöbet süreleri boyunca sürekli yeni hastaların başvurmasından dolayı çok daha uzun sürelerde KKE kullanımını sürdürmekte ve diğer birimlere göre daha kısa sürelerde KKE olmadan dinlenme alanlarında zaman geçirebilmektedir. Bu durum acil serviste KKE uyumunun daha düşük olmasını açıklayabilir. Acil serviste KKE uyumunun artırılması için nöbet sürelerinin daha kısa ve dinamik olduğu ve daha sık dinlenme aralarının olduğu bir çalışma planı yapılabilir.

Eren ve ark. 18 tarafından yapılan bir çalışmada, COVID-19 tanısı alan 82 sağlık çalışanının 58'inde (\%71) KKE’lerin eksiksiz kullanıldığı saptanmış ve bu sağlık çalışanlarının teması riskli temas olarak değerlendirilmemiştir. Çalışmamızda da benzer şekilde tüm KKE’ları eksiksiz kullanan ve KKE kullanım durumuna göre riskli temaslı olarak değerlendirilmeyen 15 kişi $(\% 35,7)$ mevcuttur; ancak KKE’lerin eksiksiz kullanılmasına rağmen bu 15 kişinin 4'ünde $(\% 26,6)$ olası vaka saptanmıştır. Oransal olarak yapılan değerlendirmede bu oran $(\% 26,6)$, hiçbir KKE'yi kullanmayıp yüksek riskli olarak değerlendirilen 25 kişide $(\% 59,5)$ görülen olası vaka oranından (5 kişi-\%20) bile fazladır. Bu durumdan KKE’lerin eksiksiz kullanılmasının COVID-19'dan korunmada tek başına yeterli olamayabileceği, bunun yanında kılavuz önerileri doğrultusunda KKE’lerin giyilme ve çıkarılma sırasına dikkat edilmesinin ve KKE’lerin tekrar kullanımı durumunda ilgili kurallara uyulmasının da önemli olduğu sonucu çıkarılabilir. ${ }^{12,13,19,20}$

\section{Çalışmamız sonucunda;}

Hastanemizdeki COVID-19 vakaları ile yakın temas içerisinde olmasına rağmen, uygun KKE kullanımına dikkat etmeyen sağlık çalışanları olduğu saptanmıştır. Hastanemiz gibi COVID-19 hastalarının bakımının yapıldı̆̆ 1 merkezlerde KKE kullanımına yönelik uyumun artırılması, COVID-19 bulaşına karşı korunmaya yönelik sağlık alg1sının geliştirilmesi için eğitimler verilmesi gerekmektedir. 
$\mathrm{Bu}$ konular ile ilgili sağlık çalışanlarının uyumu aralıklı olarak değerlendirilmeli ve gerektiğinde eğitimler tekrarlanmalıdır. Bunun yanında sağlık çalışanlarının çalışma koşulları KKE kullanımına yönelik uyumu artıracak şekilde düzenlenmelidir. Bu çalışmada temas öyküsü olan sağlık çalışanlarının çalıştığı birim ile temas arasındaki ilişki, KKE'lerin hangilerine uyumun yüksek olup hangilerine düşük olduğu, KKE eksiksiz kullanımına rağmen klinik tablo görülüp görülmediği, risk kategorisi, temas sonrasındaki takipte klinik tablo gelişip gelişmediği ve klinik tablo gelişen çalışanların prognozları konusunda literatür katkısı sağlamak amaçlandı. KKE kullanımı ile ilişkilerin daha detaylı anlaşılması için daha çok sayıda SARS-CoV-2 PCR pozitifliğinin görüldüğü daha çok sayıda sağlık çalışanının dahil edildiği çalışmalara ihtiyaç vardır.

\section{Çalışmanın kısıtlılıkları}

Tek merkezli ve erken pandemi dönemine ait bir çalışmadir.

\section{Çıkar çatışması}

Yazarlar arasında çıkar çatışması yoktur.

\section{Finansal beyan}

Yoktur.

\section{Etik kurul onayı}

Çalışma için T.C. Sağlık Bakanlığı, Sağlık Hizmetleri Genel Müdürlüğü COVID-19 Bilimsel Araştırma Değerlendirme Komisyonu'ndan 04.05.2020 tarihli ve üniversitemiz Klinik Araştırmalar Etik Kurulu'ndan 03.06.2020 tarih ve 19-08 nolu karar ile onay alınmıştır. 
J Biotechnol and Strategic Health Res. 2021;5(3):207-213

Kaynaklar

1. Lu R, Zhao X, Li J, et al. Genomic characterisation and epidemiology of 2019 novel coronavirus: implications for virus origins and receptor binding. Lancet (London, England). 2020;395(10224):565-574.

2. Zhu N, Zhang D, Wang W, et al. A Novel Coronavirus from Patients with Pneumonia in China, 2019. N Engl J Med. 2020;382(8):727-733.

3. Gorbalenya AE, Baker SC, Baric RS, et al. The species Severe acute respiratory syndrome-related coronavirus: classifying 2019-nCoV and naming it SARS-CoV-2. Nat Microbiol. 2020;5(4):536-544.

4. WHO Director-General's remarks at the media briefing on 2019-nCoV on 11 February 2020 [Internet]. [Erişim tarihi: 15 Nisan 2021]. https://www.who.int/director-general/ speeches/detail/who-director-general-s-remarks-at-the-media-briefing-on-2019-ncovon-11-february-2020

5. Situation Report-51 SITUATION IN NUMBERS total and new cases in last 24 hours [Internet]. [Erişim tarihi: 15 Nisan 2021]. https://www.who.int/docs/default-source/ coronaviruse/situation-reports/20200311-sitrep-51-covid-19.pdf?sfvrsn=1ba62e57_10

6. General Coronavirus Table [Internet]. [Erişim tarihi: 15 Nisan 2021]. https://covid19. saglik.gov.tr/EN-69532/general-coronavirus-table.html

7. Alkan Çeviker S, Dindar Demiray EK. SARS-CoV-2 (COVID 19) Enfeksiyonu Ayırıcı Tanı Açısından Diğer Solunumsal Virüsler. J Biotechinol \& Strategic Health Res. 2020; 4: 45-49.

8. Transmission characteristics and principles of infection prevention and control-COVID-19: infection prevention and control (IPC) - GOV. UK [Internet]. [Erişim tarihi: 15 Nisan 2021]. https://www.gov.uk/government/publications/wuhan-novel-coronavirus-infection-prevention-and-control

9. Zhang W, Du R-H, Li B, et al. Molecular and serological investigation of 2019-nCoV infected patients: implication of multiple shedding routes. Emerg Microbes Infect. 2020;9(1):386-389.

10. Sanche S, Lin YT, Xu C, et al. High Contagiousness and Rapid Spread of Severe Acute Respiratory Syndrome Coronavirus 2. Emerg Infect Dis. 2020;26(7):1470-1477.

11. Demir C. Meslek Hastalığı Olarak Sağlık Çalıșanlarında COVID-19 [Internet]. [Erișim tarihi: 15 Nisan 2021]. https://www.ttb.org.tr/kutuphane/covid19-rapor_6/covid19-rapor_6_Part37.pdf
12. COVID-19 Pandemisinde Sağlık Kurumlarında Calıșma Rehberi ve Enfeksiyon Kontrol Önlemleri [Internet]. [Erişim tarihi: 15 Nisan 2021]. https://covid19.saglik.gov.tr/ TR-66532/saglik-kurumlarinda-calisma-rehberi-ve-enfeksiyon-kontrol-onlemleri.html

13. FFP2 Respiratörlerin kullanımı ve yeniden kullanımı Konusunda DAS Derneği görüşü [Internet]. [Erişim tarihi: 15 Nisan 2021]. https://www.das.org.tr/index.php/das-duyurular/147-ffp2-respiratorlerin-kullanimi-ve-yeniden-kullanimi-konusunda-das-dernegi-gorusu

14. TC Sağlık Bakanlığı COVID-19 Salgın Yönetimi ve Çalışma Rehberi. Temaslı Takibi, Salgın Yönetimi, Evde Hasta İzlemi ve Filyasyon [Internet]. [Erişim tarihi: 15 Nisan 2021]. https://covid19.saglik.gov.tr/TR-66339/temasli-takibi-salgin-yonetimi-evde-hasta-izlemi-ve-filyasyon.html

15. TC Sağlık Bakanlığı COVID-19 Salgın Yönetimi ve Çalıșma Rehberi. Erișkin Hasta Tedavisi. [Internet]. [Erişim tarihi: 15 Nisan 2021]. https://covid19.saglik.gov.tr/TR-66926/ eriskin-hasta-tedavisi.html

16. TC Sağlık Bakanlığı COVID-19 Salgın Yönetimi ve Çalışma Rehberi. Genel Bilgiler, Epidemiyoloji ve Tanı. [Internet]. [Erişim tarihi: 15 Nisan 2021]. https://covid19.saglik.gov. tr/TR-66337/genel-bilgiler-epidemiyoloji-ve-tani.html

17. Folgueira MD, Muñoz-Ruipérez C, Alonso-López MÁ, et al. SARS-CoV-2 infection in Health Care Workers in a large public hospital in Madrid, Spain, during March 2020. medRxiv [Internet]. [Erişim tarihi: 16 Nisan 2021]. https://www.medrxiv.org/content/ early/2020/04/27/2020.04.07.20055723

18. Eren E, Çelik İ, Yıldız M, et al. COVID-19 Geçiren Sağlık Çalışanlarının Değerlendirilmesi Evaluation of Health Care Workers With COVID-19. Klimik Derg. 2020;33(3):230234 .

19. Using Personal Protective Equipment (PPE) | CDC. [Internet]. [Erişim tarihi: 16 Nisan 2021]. https://www.cdc.gov/coronavirus/2019-ncov/hcp/using-ppe.html

20. Recommended Guidance for Extended Use and Limited Reuse of N95 Filtering Facepiece Respirators in Healthcare Settings | NIOSH | CDC. [Internet]. [Erişim tarihi: 16 Nisan 2021]. https://www.cdc.gov/niosh/topics/hcwcontrols/recommendedguidanceextuse. $\mathrm{htm}$ 